\title{
Do the Cross-Country Interest Rate Affect Real Macroeconomic Activities? An Empirical Analysis
}

\author{
Sanjay Kumar Rout ${ }^{1 *}$, Hrushikesh Mallick ${ }^{2}$ \\ ${ }^{1,2}$ Centre for Development Studies, Prasanth Nagar, Ulloor, Thiruvananthapuram-695011, Kerala, India
}

DOI: $10.36348 /$ sjef.2021.v05i04.003

| Received: 07.03.2021 | Accepted: 03.04.2021 | Published: 06.04.2021

*Corresponding author: Sanjay Kumar Rout

\section{Abstract}

We attempt to understand the cross-country impact of interest rate on macroeconomic economic activities among a few major economies such as advanced economies (US, Japan, and Germany) and emerging economies (China, India, and Russia). Using Generalized Impulse Response analysis of VAR model, we find that advanced countries' interest rate affects economic activities relatively higher than emerging economies' interest rate. Contrastingly, among emerging economies, China's interest rate influences economic activities of all while interest rates of India and Russia have either marginal or no impact on others' aggregate economic activities, including advanced countries.

Keywords: Interest rate shocks transmission; Macroeconomic activities; Globalization; Advanced economies; Emerging economies; Impulse response function.

Copyright (C) 2021 The Author(s): This is an open-access article distributed under the terms of the Creative Commons Attribution 4.0 International License (CC BY-NC 4.0) which permits unrestricted use, distribution, and reproduction in any medium for non-commercial use provided the original author and source are credited.

\section{INTRODUCTION}

Understanding the linkage between the interest rate and macroeconomic activities is crucial in implementing open economy macroeconomic policies for any economy. The monetary authority follows an expansionary monetary policy intending to stimulate economic activities during the depression, while it follows a tight monetary policy during an inflationary period. Similarly, the fiscal authority tends to adopt an expansionary fiscal policy during the depression and a contractionary policy during the business cycle's boom phase. It implies that proper coordination of policies by monetary and fiscal authorities can contribute to maintaining macroeconomic stability. However, intensification of market integration across economies has frequently produced greater economic instability in individual economies, especially in this 21 st century. Considering the acceleration of globalization and the liberalization process, Giovanni and Shambaugh [1] point out that countries' macroeconomic stability has become interdependent. It is evident from the Asian Financial Crisis (1997-98) and the recent Global Financial Crisis (2007-09). The Global Financial Crisis (2007-09) had its origin from the subprime mortgage asset market of the US [1] and later expanded to affect many other economies [3], including high, medium, and low-income countries. Finally, both the Asian Financial Crisis and subsequently the Global Financial Crisis not only restricted to hamper the economic growth of East
Asia and the US economies respectively, where the crises had their geographic genesis but also affected the worldwide economic growth $[2,4,1]$.

Moreover, the external shocks are the primary sources of economic instability in emerging countries [5] due to increasing market integration and liberalized open economic policies in the 21 st century. In this context, understanding the cross-country interest rate effects, which believe to be crucial causes of macroeconomic fluctuations [6], may help to frame desirable policies for addressing the concerned economies' problems. When domestic interest rates integrate with the interest rates prevailing in international markets, it can affect the growth rates of economies by affecting the capital (financial flows) and real investment and trade flows. In line with Mumtaz and Surico [7], observation of the cross-country spillover effect brings the best policy for international development. Given the rising degree of globalization in this new century, this appraisal is essential to understand the impact of interest rates on aggregate

\footnotetext{
${ }^{1}$ The phrases "economic growth" and "economic activity" are used interchangeably.

${ }^{2}$ The United States' subprime mortgage crisis led by burst in housing market bubble was a multinational financial crisis that occurred between 2007 and 2010 that contributed to 2007-08 Global Financial Crisis (GFC).
} 
Sanjay Kumar Rout \& Hrushikesh Mallick., Saudi J Econ Fin, Apr, 2021; 5(4): 148-159

economic activities. Therefore, this study aims at assessing the cross-country interest rate effects on aggregate economic activities among a group of selected advanced and emerging economies. Specifically, our objective is to assess the interest rate impact of emerging countries on advanced countries' economic activities and vice-versa.

The theoretical interpretation of how one country's interest rate affects another country's economic activity has seldom received previous studies' attention. Interestingly, Iacoviello and Navarro [8] provided three channels: exchange rate, trade, and financial channels for the transmission of interest rate effects. They explained how one country's interest rate affects another country's economic activity via the exchange rate, trade, and financial channels. Mainly, literature shows that exchange rate, trade, and financial channels, are the important channels through which economic interaction can occur. Here we have emphasized the working of those channels and provide a theoretical interpretation of the same through which interest rate can affect macroeconomic activities.

First, the interest rates affecting economic activities via the exchange rate channel are based on demand substitution between home and foreign goods. With increased interest rates in the home country and following the appreciation in the domestic currency's value against foreign currency's value, it can lead to demand substitution. In other words, when the interest rate at home exceeds the interest rate prevailing abroad, the demand substitution is likely to result in where demand for home goods will substitute by demand for foreign goods. Thus, the home country's higher interest rate may lead to the expansion of economic activities abroad. For instance, appreciation of the home country's currency led by rising domestic interest rates may alter the composition of world demand by diverting demand for home goods to demand foreign goods. Under a flexible exchange rate, GDP in a foreign country would increase because of their cheaper export prices [8].

Second, the transmission of interest rates to economic activities via trade channels can occur based on the idea that a higher interest rate may decrease the incomes and expenses of the home country. It implies a lowering of the home country's demand for both home goods and imported goods, which can have a potentially debilitating effect in lessening economic activity and GDP growth rate abroad. The trade channel's strength depends on the share of exports and imports of goods and services of a foreign country with the domestic economy [8].

Lastly, the interest rate effect on economic activities via the financial channel is based on the idea that higher interest rates in the home country may transfer through prices of different financial assets and liabilities held by international agents. When the price of financial assets distorts abroad, a higher interest rate in the home country is likely to affect economic activity abroad [8]. These are fundamental interpretations through which one country's interest rate can affect the economic activity of another country. The following explores and revisits the related empirical literature in this context.

The extant literature investigates the crosscountry interest rate effects on economic growth is quite limited. Most studies have either considered the transmission between developed countries or only from developed to emerging countries in a unidirectional way without emphasizing its reverse direction. Studies by Betts and Devereux [9], Kim [10], Arora and Cerisola [11], Canova [12], Giovanni and Shambaugh [13], Mackowiak [14], Evgenidis and Siriopoulos [15], Georgiadis [16], and Dedola et al. [17] are crucial in this context. Nevertheless, a study by Samargandi and Kutan [18] on examining the spillover among BRICS belongs to one of the rare categories that investigated shocks' impact in a reverse way. Otherwise, the transmission of interest rates from emerging to developed countries has been largely ignored. At the same time, studies, in general, incorporating both the advanced and emerging countries are limited. Therefore, the critical questions are whether advanced countries' interest rates affect emerging economies' aggregate economic activities. Whether it affects positively or negatively? Whether the interest rates of emerging countries affect advanced countries' economic activities and whether it affects them positively or negatively? Answering such questions is the crucial issue in formulating individual economies' macro policies when there are cross-country interest rate effects on economies' macroeconomic activities, thereby contributing to macroeconomic instability.

Our analysis includes the samples from both the advanced and the emerging economies; the US, Japan, Germany, China, India, and Russia. These countries are the six largest countries globally by their purchasing power parity (PPP) adjusted real GDP, estimated by World Economic Outlook (April 2018) for 2017. The real PPP-adjusted GDP share of these countries makes up around $52 \%$ of the world's production. When earlier studies reveal the influence of advanced countries on other countries, the present study hypothesizes that these six large countries can also influence one another. There may exist significant linkages among them. We considered these countries because of their larger market size, which is crucial in the transmission channel. It is highlighted in the literature that a large country is likely to influence small countries but not the other way around. Therefore, they hypothesize that the market should be large enough while exploring the existence of bidirectional effects between countries. 
Sanjay Kumar Rout \& Hrushikesh Mallick., Saudi J Econ Fin, Apr, 2021; 5(4): 148-159

The economic progress of emerging economies over the last two decades is well recognized. There is a significant increase in these emerging countries' GDP share from $14 \%$ to around $30 \%$ vis-a-vis when these advanced countries' share has declined significantly from $33 \%$ to $22 \%$ between 2000 and 2017 , respectively. It is also essential to look at other economic variables central to assessing the crosscountry linkages. With rising exports and imports from emerging countries, their respective trade shares in world exports and imports make up a significant proportion. The shares of the world's exports and imports varied from $6 \%$ and $5 \%$ in 2000 to $15 \%$ and $14 \%$ respectively in 2017 . Conversely, the shares of exports and imports of advanced countries have fallen from $28 \%$ and $32 \%$ in 2000 to $20 \%$ and $21 \%$ in 2017 .

Further, the FDI inflow of advanced countries has fallen steadily from $31.39 \%$ to $27.34 \%$, while the share of emerging countries has remained stable at $12 \%$ of world FDI stock during 2010-2017. However, the role of globalization has intensified into manifolds that integrate the emerging countries with the global economy [19]. Therefore, examining this cross-country spillover from emerging economies to advanced economies bears policy significance for the advanced economies and emerging economies.

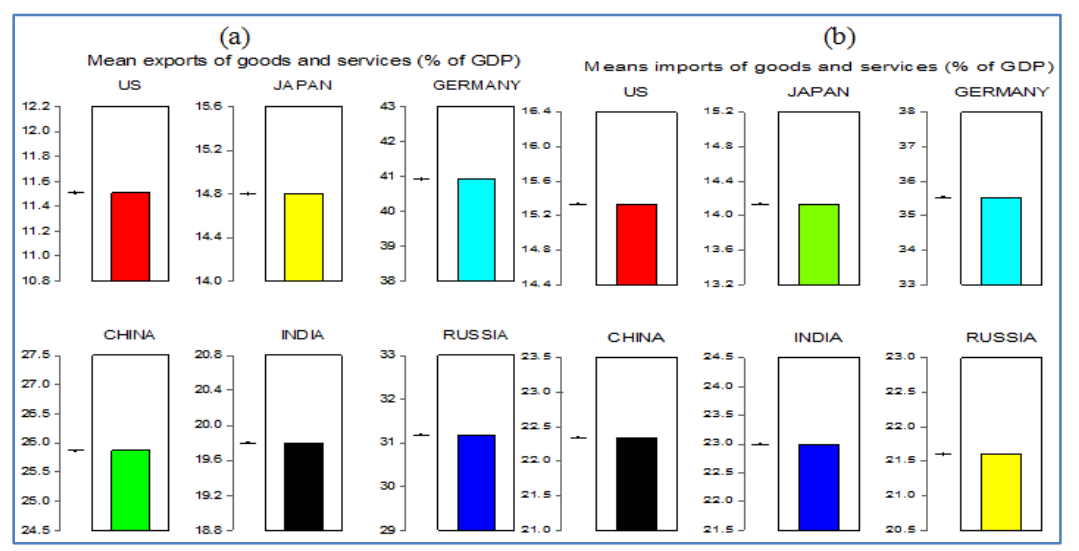

Fig-1: Mean exports and imports of goods and services

Source: Mean calculation Based on World Development Indicators (WDI), World Bank

Note Fig.-1(a) and (b) show the mean value of exports and imports of goods and services respectively as a percentage of GDP of the US, Japan, Germany, China, India, and Russia. Exports and imports of goods $\&$ services characterize the value of all goods and services delivered and imported to and from the rest of the world, which comprise the value of merchandise, insurance, freight, travel, transport, license fees, royalties, and other services, including communication, financial, construction, information, business, personal, transfer payments and government services (World Bank National Accounts) from 2000 to 2018.

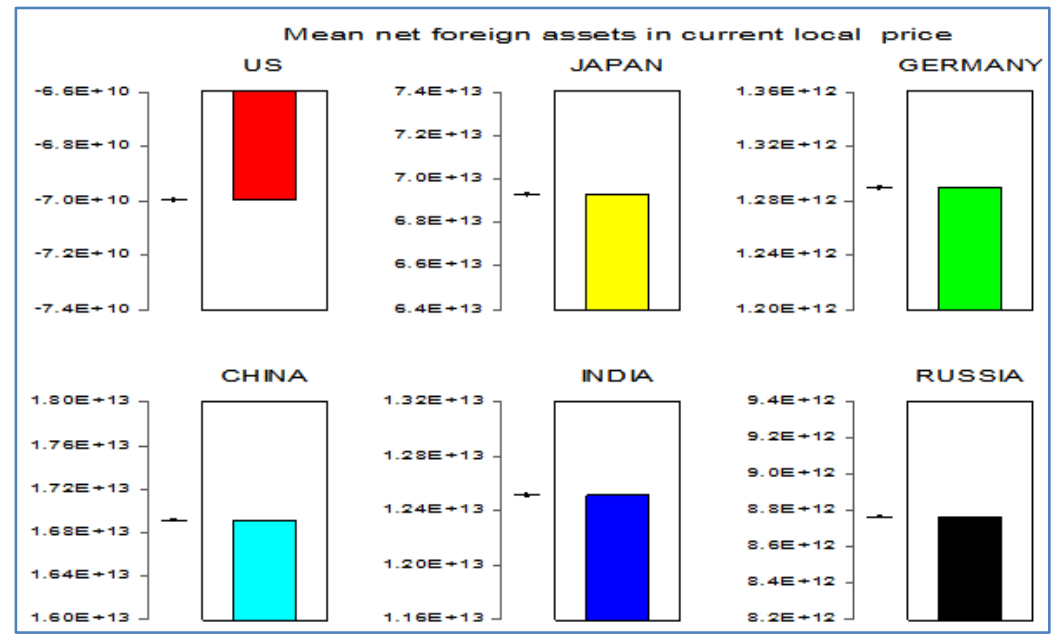

Fig-2: Mean net foreign assets

Source: mean calculation based on World Development Indicators (WDI), World Bank

Note: Fig. 2 represents the average of net foreign assets which are the sum of foreign assets held by monetary authorities and deposit money held in banks, less their foreign liabilities from 2000 to 2018. 
Sanjay Kumar Rout \& Hrushikesh Mallick., Saudi J Econ Fin, Apr, 2021; 5(4): 148-159

Fig. 1 and 2 show the mean value of exports and imports of goods and services and the average net foreign assets of the US, Japan, Germany, China, India, and Russia. The countries under consideration to a significant extent are conducting international trade and hold foreign assets. Therefore, we expect a significant impact between emerging and advanced countries with one another. Given such integration, a study of their interaction is a precondition to design economies' macroeconomic policy in this accelerated globalized and more intensified liberalized era.

We have considered the real overnight, shortterm and long-term interest rates for our empirical analysis and conducted a principal component analysis (PCA). The PCA is a multivariate data reduction technique that has been useful and important to build up a composite index [13]. We have compiled a single series of interest rates of varying maturities for each country by running PCA. The same index constructed has been used in the model. We have used this index to find out the overall cross-country interest rate effect of each country. Considering only a single maturity of interest rate across economies may not reveal an accurate picture of the economies' cross-country effects. Thus, by considering a single statistical measure (or index) of all terms of interest rates as per various maturities, it becomes easier to assess the international interest rate effects on other countries. To estimate the interest rate effect of one country on the economic activity of another, we have used the Generalized Impulse Response (GIRF) of the VAR model. The VAR model is a natural tool for macroeconomic policy study since it captures both the instantaneous association and lagged information between variables [20]. Therefore, the VAR model can uncover the true dynamic effects of the cross-country interest rate on their economic activities.

The result shows that advanced countries' interest rate affects the economic activities of both advanced and emerging economies. Specifically, advanced countries like the US and Japan positively affect economic activities of other economies. It implies that in response to one standard deviation shock in interest rate of the US and Japan, it leads to rising economic activities of other countries. Unlike the US and Japan, the interest rate of Germany affects the aggregate economic activities of other economics negatively. In contrast, the shocks in interest rate of an emerging country like China positively influence the economic activities of both advanced and emerging countries. Eventually, the impact of India and Russia's interest rate on economic activities of both advanced and emerging countries is minimal or close to zero. The latter result could be based on the latter countries' smaller share in the US's imports and investment inflows. These empirical findings are robust.
The sections are organized as follows: Section 2 presents the related empirical literature. Section 3 sheds light on methodology. Section 4 describes the set of data used in the analysis. Section 5 presents empirical findings and discussion. Section 6 discusses the robustness of our empirical findings. Section 7 concludes.

\section{Survey of Related literature}

Mundell [21], Fleming [22], and Dornbusch [23] are the early contributors to international open economy macroeconomics who have set out the most fundamental theories relating to monetary and fiscal policy transmission across economies in an international context. They try to explain how the production, employment, exchange rate, and policy boundaries of different countries are connected. They showed how an expansionary (contractionary) monetary policy leads to a rise (fall) in domestic output and employment because of depreciation (appreciation) of the real exchange rate. In turn, it affects the activities of other (foreign) economies positively (negatively).

Nevertheless, some other studies like Corsetti and Pesenti [24] provided a more complex idea in the international transmission of interest rate mechanism. Their ideas are based on micro-founded models of imperfect competition and nominal rigidity, which spell out how policy shocks spread in an open economy context from one economy to another. They claimed that an expansionary policy reduces the purchasing power of domestic consumers in global markets. Specifically, small open economies affected by the domestic nominal shocks generate imbalances in their terms of trade. On the other hand, large economies may benefit from a moderate rise in output and employment. However, if policymakers make significant monetary expansion to fill up the gaps between actual and potential output, it may reduce the purchasing power and worsen the terms of trade of domestic economies.

Betts and Devereux [9] theoretically and empirically re-examined Mundell's [21] idea in the context of a modern intertemporal optimizing stickyprice framework. They argued that the impact of monetary policy shocks on international transmission depends on the currency in which prices of exports are expressed. For instance, if export prices express by buyers' currency rather than sellers, the international transmission of monetary policy effects would significantly alter. It may lead to depreciation and thereby raising the relative prices of exports. The direction of movement in output, consumption, investment, and terms of trade may reverse. The argument put forward by Betts and Devereux will be narrow to make it worthwhile for the present analysis of the international transmission of interest rates effects. It is because cross-country inter-linkages are based not only on export prices but also on many other macro 
Sanjay Kumar Rout \& Hrushikesh Mallick., Saudi J Econ Fin, Apr, 2021; 5(4): 148-159

variables. It is connected directly/indirectly with other countries not covered by such studies.

Empirically, Betts and Devereux [9] and Kim [10] showed that US monetary expansion spurs non-US economies' output. Both the studies postulate that when a large open economy adopts an expansionary policy, it decreases the world real interest rate. That, in turn, stimulates the real economic activities of both domestic and foreign countries. Kim also examined two channels: trade balance and world aggregate demand channels (via world real interest rate). He found the latter plays a vital role in the transmission of the US monetary policy shocks. However, Arora and Cerisola [11] expanded the analysis from advanced to developing countries. They examined how US monetary policy changes affect the country risk and economic growth in developing countries of Latin America, Asia, and Eastern Europe. They noted that the US interest rate has a significant impact on the economic growth of developing countries. Nevertheless, most of these analyses have undermined the role of developing countries in the world economy.

Canova [12] examined the extent and importance of financial and trade channels in the transmission of US structural disturbances and their effects on several Latin American countries. They stated that the US's monetary shock explains more significant variations in Latin American countries' macroeconomic variables. Further, under different exchange rate regimes, Giovanni and Shambaugh [12] analyzed the effects of base countries' short-term interest rates (10 major economies) on other countries' annual real GDP. They confirmed that if the interest rate is higher by one percentage-point in base countries, it will decline the annual GDP growth rate by 0.20 percentage points in other countries. They also traced out the importance of pegged exchange rates than floating exchange rates in the transmission system. However, this is a unidirectional analysis as it has remained silent on the bidirectional effects.

Some recent studies were carried out exploring the linkage between advanced and emerging or only between advanced countries. They tried to establish the link from a unidirectional perspective. For instance, Mackowiak [14] analyzed whether the US monetary policy shocks can explain much of the macroeconomic fluctuations in emerging markets. They found the external shocks explained around $40 \%$ in real output. In contrast, examining the international transmission of the US contractionary monetary policy effects and all its transmission channels across the Euro area and Asian countries, Evgenidis and Siriopoulos [15] revealed an increase in US short-term rate positively affects GDP in the entire EU and some East Asian countries. Similarly, Georgiadis [16] analyzed how global spillover from US monetary shocks (interest rates) depends on countries' macroeconomic characteristics. They noted that the US monetary policy spreads to the rest of the world and significantly affects other countries' output.

Dedola et al. [17] examined the US's monetary policy shocks spillover to a broad set of macroeconomic and financial variables in 36 countries (18 advance and 18 emerging countries) to evaluate the macroeconomic features. They showed that a contractionary US monetary policy leads to a fall in industrial production and real GDP. Samargandi and Kutan [18] also analyzed private credit shock transmission and its impact on economic growth between BRICS countries. They observed that credit to the private sector in one country has a positive impact across BRICS countries.

Previous studies on cross-country interest rate linkage skipped out the important dimension in the transmission channels through which the shocks transmitted from one country to another involving from advanced to the developing and vice-versa. Exceptionally, Iacoviello and Navarro [8] tried to address the importance of channels. They examined the spillover of interest rates originating from the US surprises to 50 advanced and emerging countries depending on the exchange rate, trade, and financial channels. Further, they argued that if the US federal fund rate rises by 100 basis points, it lessens the GDP growth of both the advanced and emerging countries by $0.5 \%$ and $0.8 \%$. Specifically, the effects of higher interest rates pass on to the advanced countries through exchange rate and trade, while the effects spread to the emerging countries through the financial channel.

\section{METHODOLOGY}

To analyse the cross-country interest rate effects on economic activities, we have employed GIRF of the VAR model. To estimate the model, one needs to understand the general form of the VAR model introduced by Sims [25]. It expressed as follows,

$$
\begin{gathered}
Z_{t}=\mathbf{b}+\boldsymbol{A}_{\mathbf{1}} Z_{t-1}+\boldsymbol{A}_{\mathbf{2}} Z_{t-2}+\ldots+\boldsymbol{A}_{\boldsymbol{p}} Z_{t-p}+\varepsilon_{t, \ldots(1)} \\
t=0,1,2 \ldots \ldots \ldots \ldots
\end{gathered}
$$

Where $Z_{t}=\left(Z_{1 t}, Z_{2 t}, Z_{3 t} \text {--------- } Z_{k t}\right)^{\prime}$ is a $\mathrm{K} \times 1$ (Note $\mathrm{K}=6$ ) random vector. $\boldsymbol{A}_{\boldsymbol{i}}$ is the constant $\mathrm{K} \times \mathrm{K}$ coefficient matrix. $\mathbf{b}=\left(b_{1}, b_{2} \text {------- } b_{K}\right)^{\prime}$ is a constant

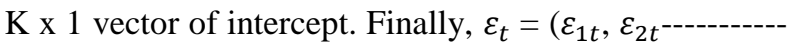
$\left.\varepsilon_{k t}\right)^{\prime}$ is a $\mathrm{K}$ - dimensional white noise where $\mathrm{E}\left(\varepsilon_{t}\right)=0$, the variance covariance matrix at time $t, \mathrm{E}\left(\varepsilon_{t}, \varepsilon_{t}^{\prime}\right)=\Sigma_{\varepsilon}$ is a positive definite matrix and $\mathrm{E}\left(\varepsilon_{t}, \varepsilon^{\prime}{ }_{s}\right)=0$ for all $t \neq s$.

Model is said to be stable if all eigen-values of $A_{i}$ should have less than 1 that is

$$
\operatorname{det}\left(\boldsymbol{I}_{\boldsymbol{K}}-\boldsymbol{A}_{\boldsymbol{i}} \lambda\right) \neq 0 \quad \text { for }|\lambda| \leq 1
$$

The model is mentioned by considering the interest rate and growth rate of six countries. Equation 
Sanjay Kumar Rout \& Hrushikesh Mallick., Saudi J Econ Fin, Apr, 2021; 5(4): 148-159

(1) can be expressed as Vector Moving Average (MA $(\infty))$, under stability condition.

$Z_{t}=\mu+\sum_{i=0}^{\infty} A_{i}^{i} \varepsilon_{t-i}$

Where, $\mu=\left(I_{K}-A_{i} \mathrm{~L}\right)^{-1} \mathbf{b}$

The sequence $Z_{t}$ comprises of past and present error vectors $\left(\varepsilon_{t}\right)$ in this VMA representation. Therefore, equation (2) rewritten as:

$Z_{t}=\Phi(\mathrm{L}) \varepsilon_{t}$

Where $\Phi(\mathrm{L})$ is a polynomial or lag operator such that $\Phi(\mathrm{L})=\sum_{i=0}^{\infty} A_{i}^{i} L^{i}$.

The coefficients $(\Phi)$ in equation (3) are the impulse responses of the system or $\emptyset_{j k, i}$ the $j k^{\text {th }}$ element of $\Phi_{i}$ which represents the response of $j^{t h}$ variable of the system to a unit shock of variable $\mathrm{k}, i^{\text {th }}$ period ago. However, due to the ordering problem (under orthogonal impulse response ${ }^{2}$ ) of 12 variables for six countries, we applied GIRF to estimate the cross-country impact of interest rate on economic activity. Now, using equation (3), GIRF can be written as:

$G I_{Z}\left(h, \delta_{j}, \mathrm{u}_{t-1}\right)=\mathrm{E}\left(Z_{t+h} / \varepsilon_{j t}=\delta_{j}, \mathrm{u}_{t-1}-\mathrm{E}\left(Z_{t+h} / \mathrm{u}_{t-1}\right)\right.$-------- (4) Where $G I_{X}=$ Functional notation of generalized impulse of $\mathrm{Z}$ variable

$h$, = time horizon

$\delta_{j} \quad=$ size of shocks

$\mathrm{u}_{t-1}=$ Set of information available at time $\mathrm{t}-1$.

Equation (4) is the difference between two conditional expectations themselves of which are random variables. Here, we assume that shocks are given only to $\mathrm{j}^{\text {th }}$ element, despite giving shocks to all the elements in $\varepsilon$. The effects of other shocks integrated out assuming an observed distribution of errors. The $\mathrm{E}$ ( $\left.\mathrm{Z}_{\mathrm{t}+\mathrm{h}} / \varepsilon_{\mathrm{jt}}=\delta_{\mathrm{j}}, \mathrm{u}_{\mathrm{t}-1}\right)$ implies that one is taking expectation which is conditional to the information set $\mathrm{u}_{\mathrm{t}-1}$ and for a fixed value of $\mathrm{j}^{\mathrm{th}}$ shock at time " $\mathrm{t}$ ", while integrating out all the contemporaneous and future shocks. Now, assuming that shocks term follows a multivariate normal distribution, it can be shown as:

$\mathrm{E}\left(\varepsilon_{\mathrm{t}} / \varepsilon_{\mathrm{jt}}=\delta_{\mathrm{j}}\right)=\left(\sigma_{1 \mathrm{j}}, \sigma_{2 \mathrm{j}}\right.$ $=\Sigma_{\varepsilon} \mathrm{e}_{\mathrm{j}} \sigma_{\mathrm{jj}}^{-1} \delta_{\mathrm{j}}$

Therefore, GIRF of the effect of shocks to $\mathrm{j}^{\text {th }}$ disturbance term at a time' $t$ ' on $t+h$ for the multivariate linear model is given by:

\footnotetext{
${ }^{2}$ The orthogonalized impulse response function is very much sensitive to ordering of variables which leads to inconclusive problems in the empirical analyses. Therefore, it is appropriate to use generalised impulse response function which is order insensitive.
}

$\left(\frac{\Pi_{\mathrm{h}} \Sigma_{\varepsilon} \mathrm{e}_{\mathrm{j}}}{\sqrt{\sigma_{\mathrm{jj}}}}\right)\left(\frac{\delta_{\mathrm{j}}}{\sqrt{\sigma_{\mathrm{jj}}}}\right) \mathrm{h}=0,1,2$

Thus, by scaling GIRF by $\frac{\delta_{\mathrm{j}}}{\sqrt{\sigma_{\mathrm{jj}}}}$, one can obtain the effect of a unit shock to $\mathrm{j}^{\text {th }}$ error term on $\mathrm{Z}_{\mathrm{t}+\mathrm{h}}$ which is given by

$\emptyset_{\mathrm{j}}^{\mathrm{g}}(\mathrm{h})=\sigma_{\mathrm{jj}}^{-1 / 2} \Pi_{\mathrm{h}} \Sigma_{\varepsilon} \mathrm{e}_{\mathrm{j}}$

Equation-7 measures the effect of one standard error shock to $\mathrm{j}^{\text {th }}$ equation at a time $\mathrm{t}$ on the expected value of $\mathrm{Z}$ at a time $\mathrm{t}+\mathrm{h}$. This would give us crosscountry impacts of interest rates on economic activities.

\section{Data source and description}

For the study, data set include GDP growth (economic activity), real overnight, short-term and long-term interest rates [3], and consumer price index (CPI), S\&P Global Equity Indices, and real effective exchange rate. The real GDP growth rate for the US, Japan, Germany, China and India are collected from the Organization for Economic Cooperation and Development (OECD) database with a quarterly frequency. For Russia, data is extracted from the World Bank's World Development Indicators (WB) with an annual frequency from 2000 to 2005 and whereas, the data from 2006Q1 to 2018Q2 is collected from the OECD database with a quarterly frequency.

The statistics on overnight, short-term, and long-term interest rates are drawn from the OECD database [4]. The Short-term interest rate series of India is taken from the International Financial Statistics of IMF. The long-term interest rate data set for China, India, and Russia are taken from "Investing.com" with a daily frequency. All the nominal interest rate series are drawn and then, converted into real value by subtracting the inflation rate (CPI) [5]. CPI data is collected from the OECD database with a quarterly frequency. The effective exchange rate data is drawn from the FRED database with a monthly frequency [6]. S \& P global equity indices data are drawn from the World Bank's World Development Indicator [7](annually).

\footnotetext{
${ }^{3}$ The overnight interest rate defined as the rate of interest charged on less than 24-hour call money or interbank lending rate for all the countries. The short term interest rates refer to 3-month money market rates. Long term interest rates include the quarterly yield on 10 years Government bond/securities.

${ }^{4}$ Data is extracted from Organisation for Economic Cooperation and Development (OECD).

${ }^{5}$ The consumer price index (CPI) is considered as to represent the price level for all the countries and the intuition behind using CPI as a measure of price level is; it covers prices of both goods and services comprehensively than any other measure of prices.

${ }^{6}$ Link: https://fred.stlouisfed.org

7 Data extracted from World Development Indicators/ http://databank.worldbank.org
} 
Sanjay Kumar Rout \& Hrushikesh Mallick., Saudi J Econ Fin, Apr, 2021; 5(4): 148-159

All the daily and monthly frequency data are converted into quarterly by taking their averages. Annual data are converted into quarterly by using a cubic spline interpolation method. Finally, all the data used for the analysis are considered with quarterly frequency during 2000Q1-2018Q2.Thus, it has 74 observations in each series.

\section{RESULTS AND DISCUSSION}

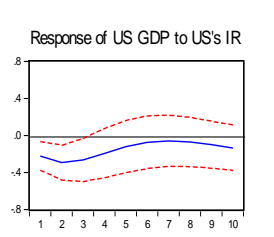

Response of Japan GDP to US IR

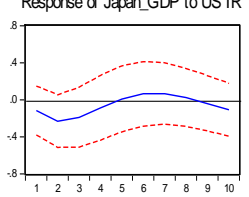

Response of Germany GDP to US IR

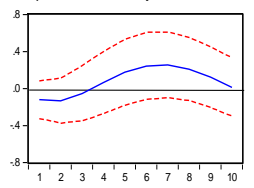

Response of China_GDP to US_IRI

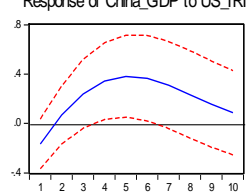

Response of India_GDP to US_IR

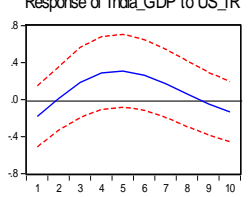

Response of Russia_GDP to US_IRI

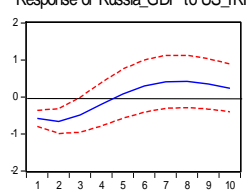

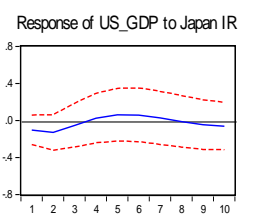

Response of Japan_GDP to Japan IR
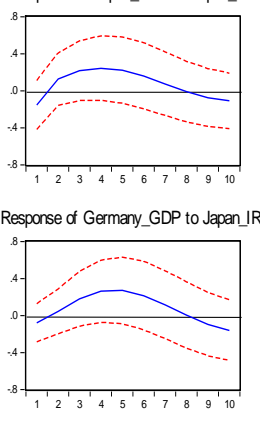

Response of China_GDP to Japan IR

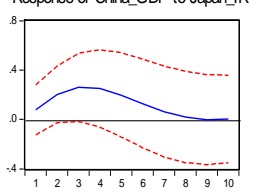

Response of India_GDP to Japan_IR

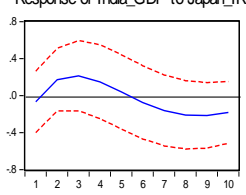

Response of Russia GDP to Japan

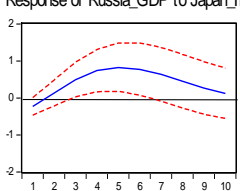

Response to Generalized One S.D. Innov ations \pm 2 S.E.

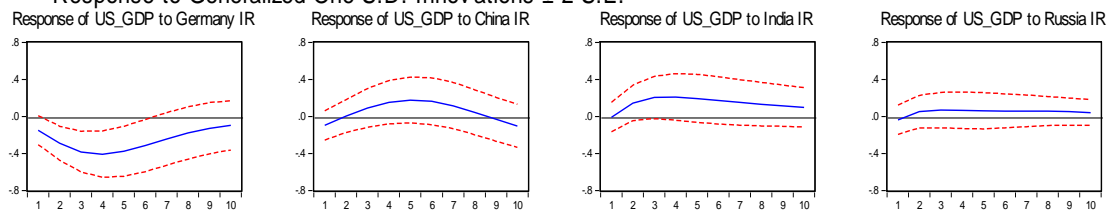

$\begin{array}{llllllllll}1 & 2 & 3 & 4 & 5 & 6 & 7 & 8 & 9 & 10\end{array}$

Response of Japan GDP to Germany IR Response of Japan_GDP to China_IR

Response of Japan_GDP to India_IRI

Response of Japan_GDP to Russia_IR

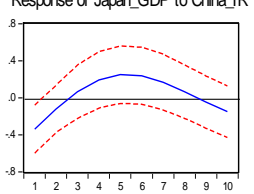

Response of Germany GDP to China IR

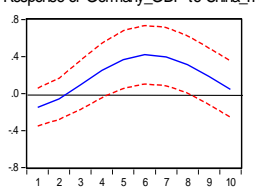

Response of China_GDP to China IR

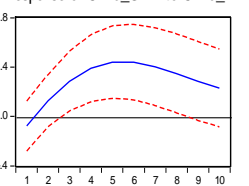

Response of India_GDP to China_IR

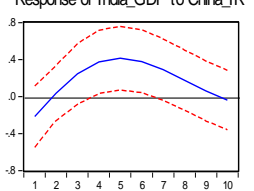

Response of Russia_GDP to China IR

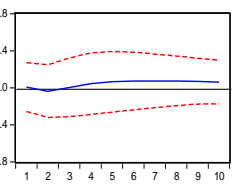

Response of Germany GDP to India IR

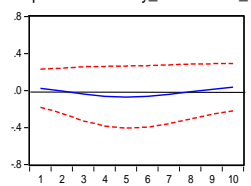

Response of China_GDP to India IR

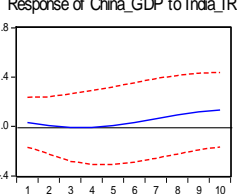

Response of India_GDP to India IR

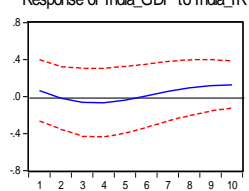

Response of Russia GDP to India IR

Response of Russia_GDP to Germany_
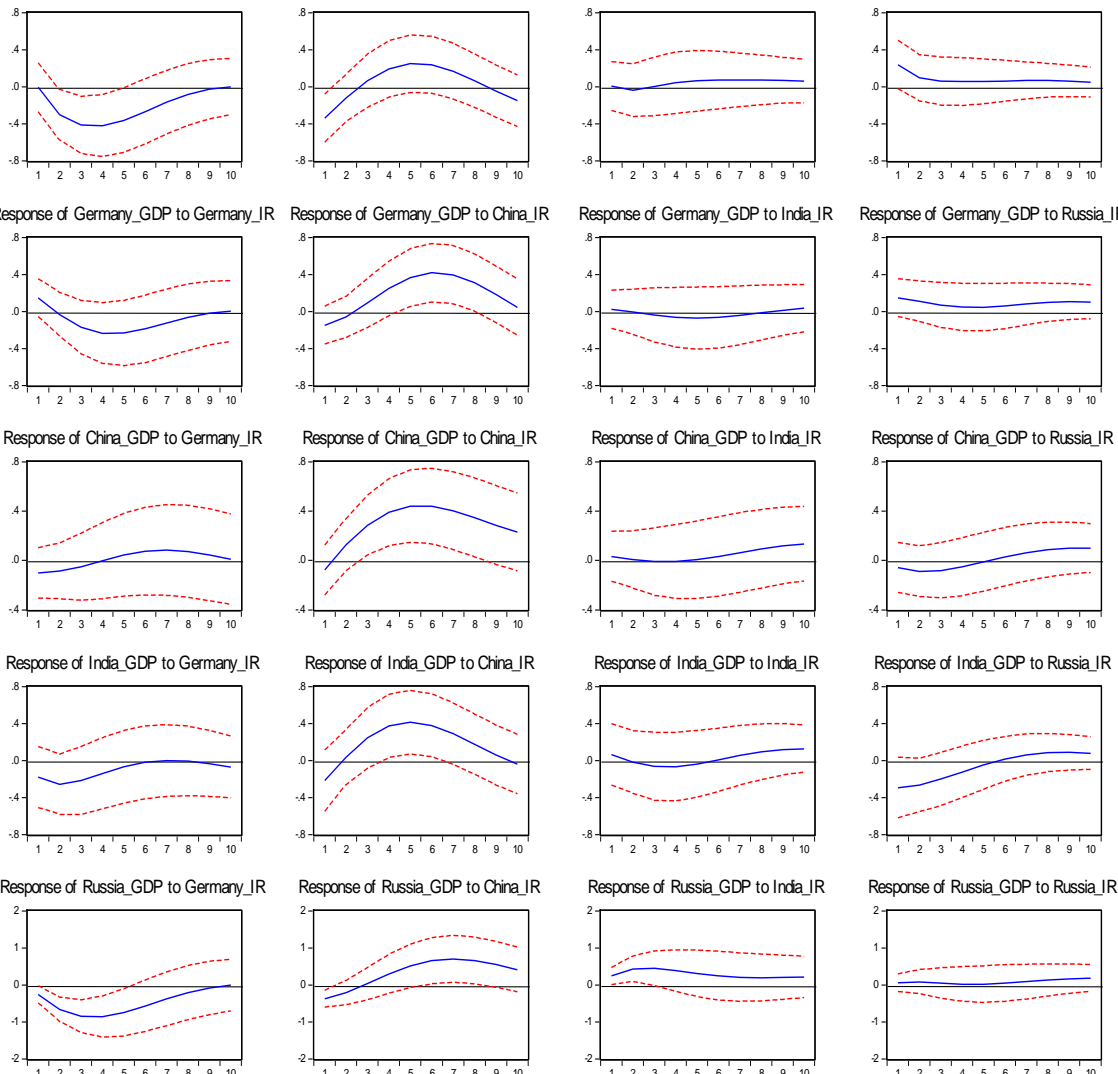

Response of Germany_GDP to Russia IF

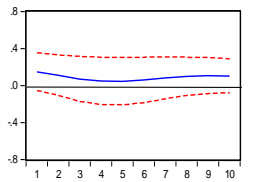

Response of China_GDP to Russia_IR

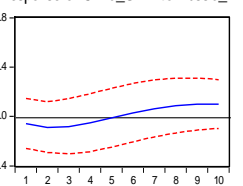

Response of India_GDP to Russia_IR

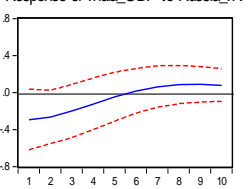

Response of Russia_GDP to Russia_IR
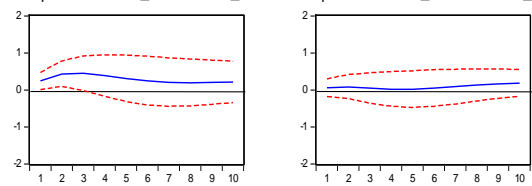

Fig-3: Generalised response of aggregate economic activities to interest rate (IR) shocks

Note: Fig.3 shows GIRF of economic activities of US, Japan, Germany, China, India, and Russia response to one standard deviation shock in US's, Japan's, Germany's, China's, India's, and Russia's interest rates (IR). Fig. 3 is based on the GIRF of the VAR model over ten quarters. Each graph produces a point estimation of GIRF with lower and upper bounds of $95 \%$ confidence interval. The blue solid line depicts the percentage response of growth rate of 6 countries to one standard deviation shock in all the IRs. The red dotted lines show $95 \%$ error bands. The vertical and horizontal axis represents the impulse responses of aggregate economic activities of different countries over time. It is noticed that the estimated model is stable (see Fig. A1 in Appendix).
The first column in Fig.1 shows the responses of economic activities (i.e., GDP growth rate) of the US, Japan, Germany, China, India, and Russia to one standard deviation shock in the US's interest rate. The US's growth rate response to its interest rate is negative over the entire 10 quarters. It is significantly negative over two quarters, and it becomes insignificant after that. The negative response may work in two ways. A rise in the interest rate may contract investment, employment, and income of people. In turn, that may affect economic growth negatively. Second, a rise in the US's interest rate leads to an appreciation of the US's currency, which may alter the composition of world demand. It can divert away from demanding the US goods to foreign goods. Under a flexible exchange rate, 
Sanjay Kumar Rout \& Hrushikesh Mallick., Saudi J Econ Fin, Apr, 2021; 5(4): 148-159

GDP in a foreign country would increase because of their cheaper export prices [8]. Therefore, the US's economic activity's response to its interest rate is negative over 10 quarters.

However, the early response (over second and third quarters) of Japan, Germany, China, India, and Russia to the US's interest rate is negative. In other words, when the interest rate rises in the US, the growth rate falls in Japan, Germany, China, India, and Russia over two quarters. Beyond the second quarter (or 3rd quarter sometimes), the responses of Japan, Germany, China, India, and Russia remain positive for the rest of the quarters. The pattern of responses explains that an increase in the US's interest rate is likely to attract significant foreign capital inflows to the US on the one hand. On the other, an induced outflow of capital from Japan, Germany, China, India, and Russia leads to a fall in their economic activities. However, with a time lag, economic activities are likely to pick up in these countries because of the appreciation of the US's currency in response to an initial period rise in interest rate. This appreciation of the US currency can make its exportables costlier and goods in the foreign market cheaper. So, global demand will be diverted away from domestic goods to foreign goods. As a result, the foreign economic activities of Japan, Germany, China, India, and Russia would expand over the long run.

The second column in Fig.1 shows that the US, Japan, Germany, China, India, and Russia's economic activities to one standard deviation shock in Japan's interest rate. The impact of the rising interest rate in Japan on the US's economic activities is close to zero. However, unlike the US, Japan's response to its interest rate is positive between the 1 st to 8 th horizons, although the immediate response is negative. Japan may attract substantial capital inflows from foreign countries following its upward revision in its interest rate, thereby stimulating its economic activity. Similarly, the impact of Japan's interest rate on Germany, China, and Russia is positive. The higher interest rate in Japan leads to expanding economic activities in Germany, China, and Russia. For instance, a rise in Japan's interest rate can cause an appreciation of its currency and alter the composition of world demand in favor of other countries. It can occur by diverting away from the demand for goods and services produced in Japan towards foreign-produced goods. Thus, the response of the economic activity of Germany, China, and Russia becomes positive. However, India's economic activities rise over the fifth quarter onwards, and then after few horizons, the expansion of economic activities in India declines following one standard deviation shock in Japan's interest rate.

The third column in Fig. 1 shows the responses of the US, Japan, Germany, China, India, and Russia's economic activities to one standard deviation shock in Germany's interest rate. It suggests that following one standard deviation shock in Germany's interest rate, the US, Japan, China, India, and Russia's economic activities are negative on the immediate horizon. Even though the growth rate of Germany falls in response to a rise in Germany's interest rate, but in response to the impact of such a rising interest rate of Germany, there is a strong and negative reaction of macroeconomic activities in the US, Japan, and Russia as it indicates from a downward direction of impulse response trend. Nevertheless, over a longer horizon, the growth rate of economic activities for all the countries under study are found to move towards the steady-state level. This negative response may explain the link between the interest rate and investment relationship in Germany. That is a rise in interest rate, contracts out the people's investment, employment, and income. Therefore, it adversely affects the economic growth of other major economies interlinked with Germany. Similarly, the rise in Germany's interest rate attracts foreign capital and leads to the outflow of capital from the US, Japan, China, India, and Russia to Germany. It affects their economic activities negatively.

The fourth column in Fig.1 shows the responses of economic activities of the US, Japan, Germany, China, India, and Russia to one standard deviation shock in China's interest rate. The immediate impact of China's rising interest rate on the US, Japan, Germany, China, India, and Russia are negative, and beyond the 1st quarter, the impact is observed to be positive. This is because China follows the exchange rate within a fixed band leading to less volatility of its own currency. Therefore, following any interest rate rise in China leads to more significant capital inflows and economic activity growth. When the economic activity grows in China, it augments the national income and high imports from foreign countries. Hence, economic activity in foreign countries also grows positively in reaction to China's rising interest rate.

The fifth column of Fig.1 shows the response of economic activities of the US, Japan, Germany, China, India, and Russia to one standard deviation shock in India's interest rate. It shows that the economic activity rises to some extent in the US following one standard deviation shock in India's interest rate. However, Japan, Germany, China, and Russia's response to India's interest rate is close to zero. In the sixth column of Fig.1, the US, Japan, and Germany's response to Russia's interest rate is also close to zero. In contrast, the response of China's and India's growth rate to shock in Russia's interest rate is found to be negative over the fifth quarter, and then, responses are found to be positive.

In sum, the above analysis demonstrates that advanced countries' interest rate significantly affects the macro-economic activities of both the advanced and the emerging economies. Specifically, the interest rates of advanced countries like the US and Japan positively 
Sanjay Kumar Rout \& Hrushikesh Mallick., Saudi J Econ Fin, Apr, 2021; 5(4): 148-159

affect other countries' economic activity. It implies that when one standard deviation shock is given to the US's and Japan's interest rate, the economic activities of Japan, Germany, China, India, and Russia rise. Unlike the US and Japan, Germany's interest rate affects the economic activities of the US, Japan, and the developing economies economic activities in China, India, and Russia negatively. On the other hand, the interest rate of an emerging economy like China affects both advanced and emerging countries' economic activities positively. Eventually, the impact of interest rates of India and Russia on the economic activities of both the advanced and emerging countries is insignificant or close to zero (as shown in Fig. 1).

\section{Robustness check}

Response to Generalized One S.D. Innovations \pm 2 S.E.

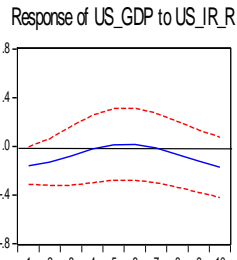

The
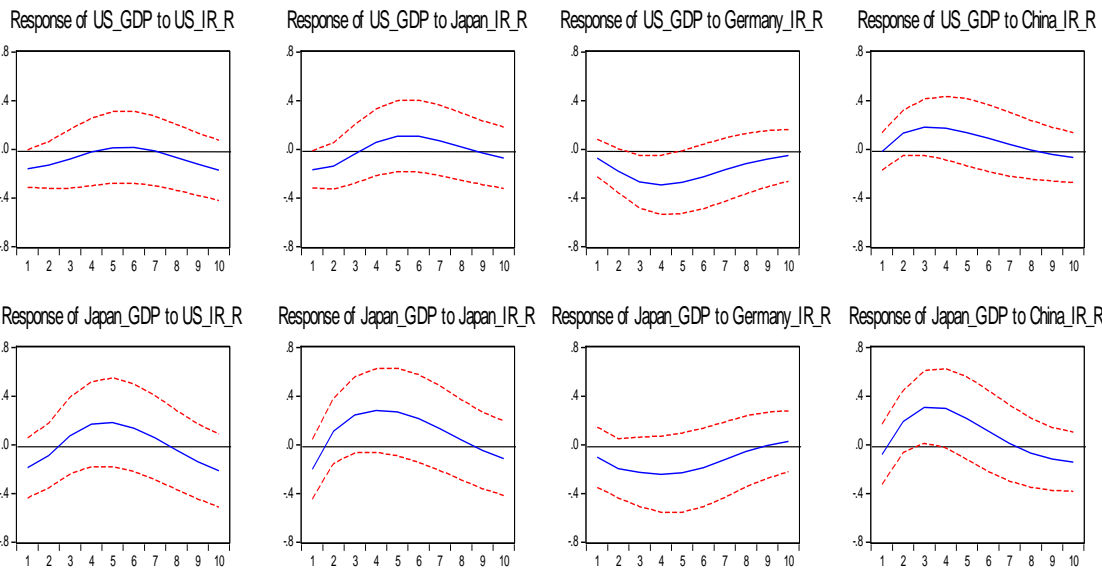

Response of Japan_GDP to Japan_IR_R Response of Japan_GDP to Germany_IR_R Response of Japan_GDP to China IR_R
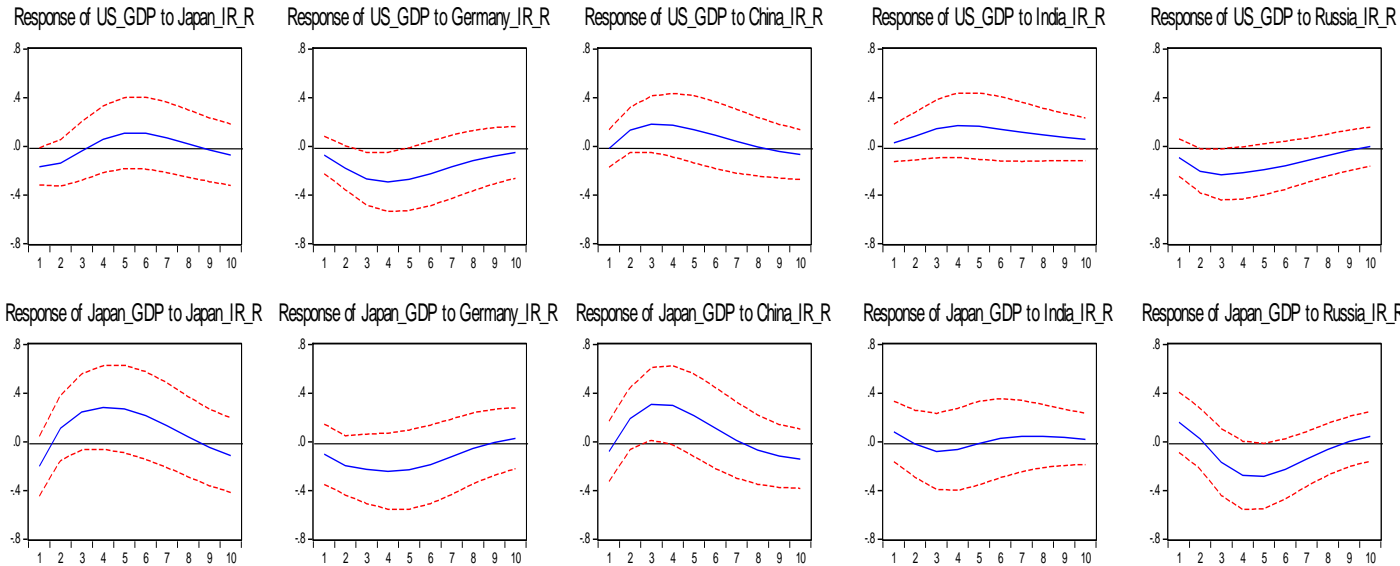

Response of Japan GDP to India IR $R$
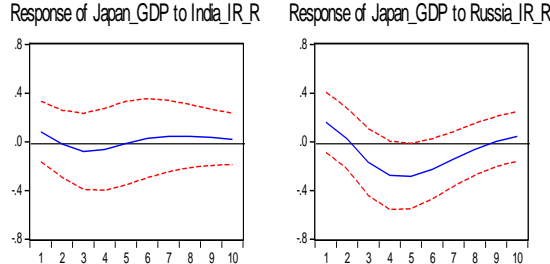

Response of Germany_GDP to US_IR_R Response of Germany_GDP to Japan_IR_Response of Germany_GDP to Germany_IR_R Response of Germany_GDP to China_IR_R Response of Germany_GDP to India_R_R Response of Germany_GDP to Russia_IR_F
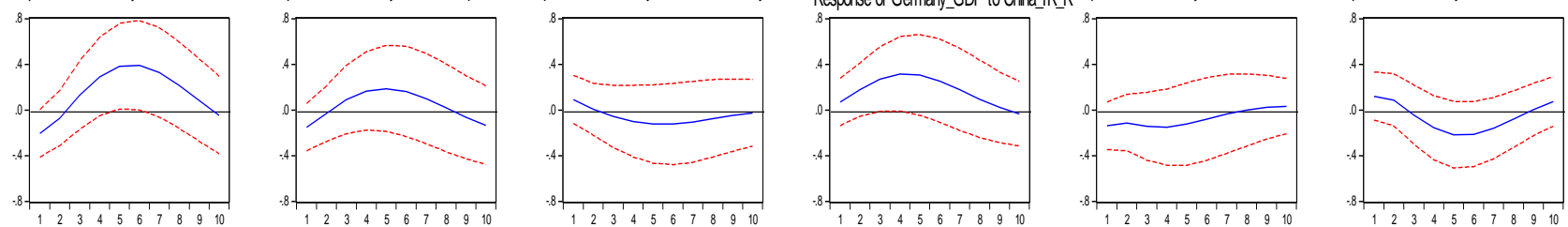

Response of China GDP to US_IR R
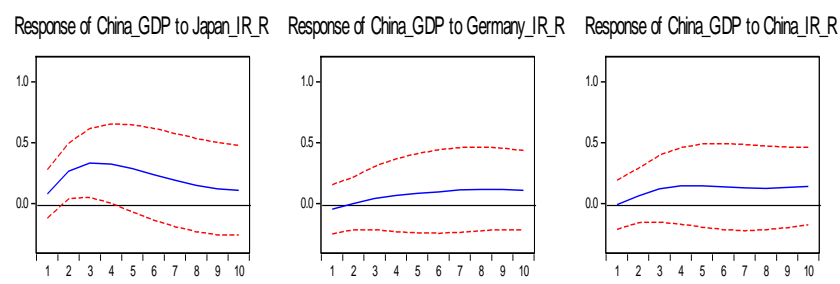

Response of China_GDP to India IR_ _

Response of China GDP to Russia_IR_R
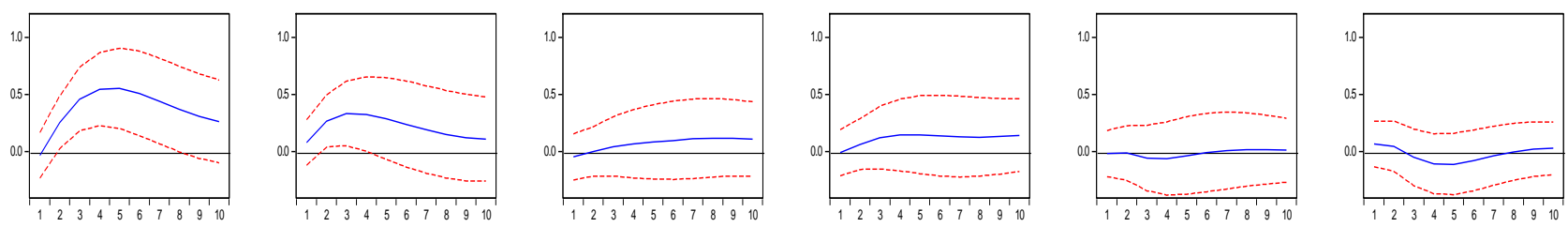

Response of India_GDP to US_IR_R
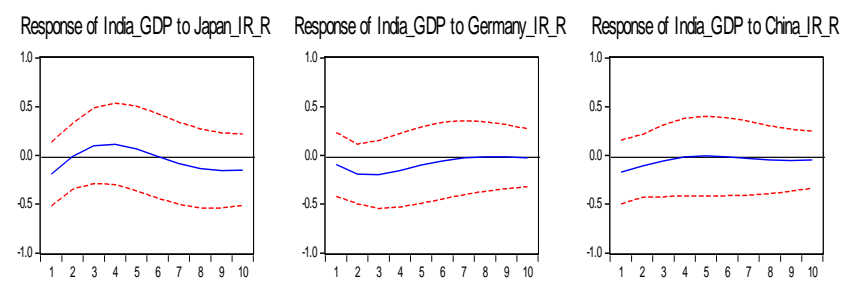

Response of India GDP to Inda IR_

Response of Inda_GDP to Russia IR R

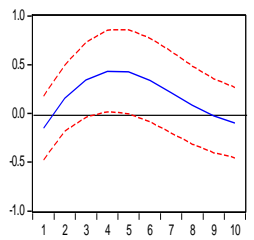

$$
\begin{array}{lllllllllll}
2 & 3 & 4 & 5 & 6 & 7 & 8 & 9 & 10
\end{array}
$$
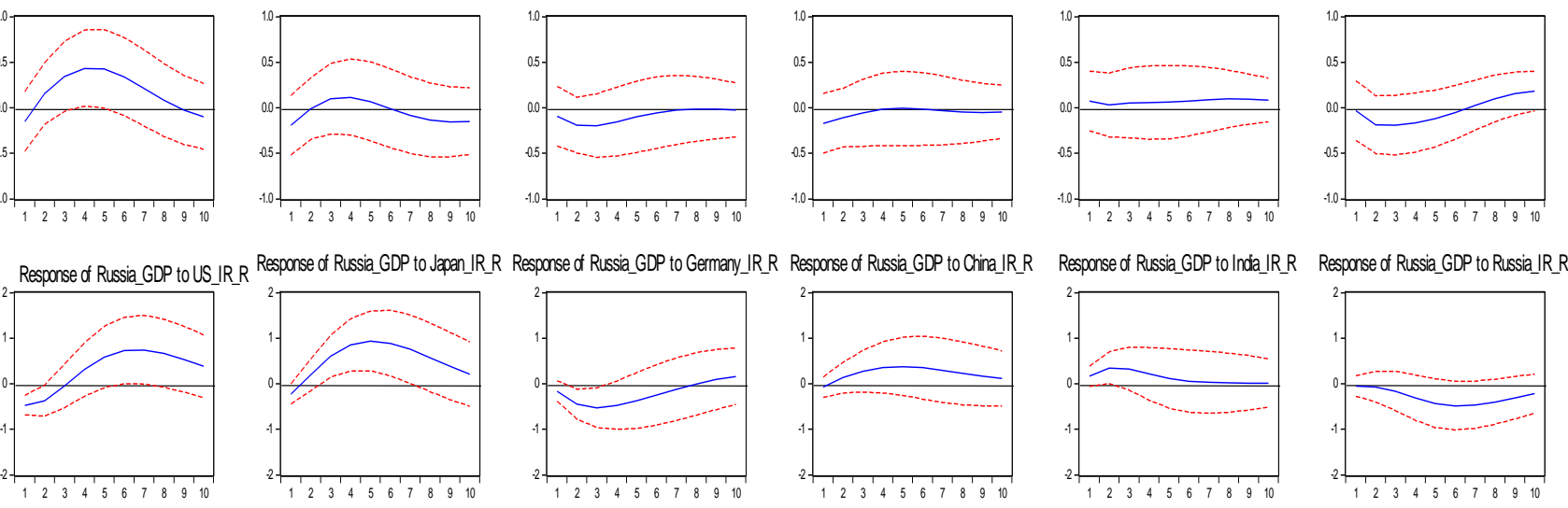

Fig-4: Response of aggregate economic activities to interest rate (IR_R) Source: Author's own estimation 
Sanjay Kumar Rout \& Hrushikesh Mallick., Saudi J Econ Fin, Apr, 2021; 5(4): 148-159

Note: Fig.4 shows the GIRF of economic activities of the US, Japan, Germany, China, India, and Russia in response to one standard deviation shocks in the US's, Japan's, Germany's, China's, India's financial variables. The financial variables include real overnight, short-run, long-term interest rate, CPI, effective exchange rate, and S\&P global equity indices. Fig. 4 is based on the GIRF of the VAR model over 10 quarters. Each graph produces a point estimate of GIRF with lower and upper bounds with a 95\% confidence interval. The blue solid line depicts the percentage response of six countries' growth rate to one standard deviation shock in the interest rate index, while the red dotted lines show 95\% confidence error bands. The vertical and horizontal axes represent the impulse responses of the growth rate of different countries over time. It can be noted that the estimated model is stable (see Fig. A2 in Appendix), and this model confirms the robustness of our initial empirical findings.

Utilizing the PCA analysis, we also estimated an alternative model by considering the leading indicator of some important financial variables from each economy separately to evaluate our initial empirical results' robustness. The financial variables include the variables used in the above standard benchmark model plus the additional variables such as $\mathrm{CPI}$, the log of the real effective exchange rate, and S \& $P$ global equity indices. These variables are very sensitive to cross-country interactions. However, after constructing the leading financial series through PCA analysis for each country, we re-estimated the same model. In the model, six PCA scores for each of the six countries are used. All the variables in the model are treated as endogenous. The estimated model is also checked for its parameter estimates' stability (see Fig. A2 in Appendix).

The result of the alternative model almost resembles the result emerging from our above model. The response of economic activities of the US, Japan, Germany, China, India, and Russia remains positive following one standard deviation shock in the US's, Japan's, and China's financial variables. The response to Germany's and Russia's interest rate is negative, while that of India's financial variable remains close to zero. These findings are similar to that of the original model of interest rate except for the impact of Russia's interest rate. In the base model, the impact of Russia's interest rate is either positive or close to zero, while with this alternative model, the impact remains primarily negative. In other cases, the empirical estimates remain unchanged, proving the robustness of our initial findings.

\section{CONCLUSION}

This paper tried to evaluate whether there exist cross-country interdependencies among selected six major economies by considering the effects of their interest rates of each of individual economies on macroeconomic activities of other economies other than the country in question whose shock is examined out of the US, Japan, Germany, China, India, and Russia. It employed the GIRF of the VAR model to explore the issue. The result shows that advanced countries' interest rate affects the economic activities of both advanced and emerging economies. Specifically, the interest rates of advanced countries like the US and Japan positively affect the economic activities of other economies. It implies that with one standard deviation interest rate shock to the US and Japan, the economic activities of Japan, Germany, China, India, and Russia rise.

Unlike the US and Japan, Germany's interest rate adversely affects the economic activities of the US, Japan, China, India, and Russia. On the other hand, the interest rate of an emerging country like China positively affects both the advanced and emerging countries' economic activities. This is a surprising finding emerging from the analysis, which was ignored or unexplored in the literature. Eventually, the impact of India and Russia's interest rates on the economic activities of both the advanced and emerging countries under study are observed to be insignificant or close to zero. Moreover, these results are robust with the change of models (by changing financial macro variables) in the analysis.

Our empirical investigation has significant policy bearing with changing currents of globalization and capital flows. It thereby significantly contributes to the literature by understanding how international interest rates affect the emerging Asian economies like China and India and, in turn, how do they affect the economic activities of advanced economies. Since the interest rate and its impact on growth rate in these large markets have often been a significant policy concern to both monetary and fiscal authorities of economies, the concerned authorities should not ignore the crosscountry effects and international interdependencies with changing market integration across economies. It suggests that the strict macroeconomic policy is the need of the hour to monitor the macro-economic indicators of economies because foreign interest rates can influence each economy's economic activities. The study clearly shows the rise and falls in an individual country's economic activity because of a rise or fall in another country's interest rate. This could imply deeper financial market integration among economies comparing the prior financial market environment that existed one or two decades ago. It cautions the policymakers to remain alert about external shocks coming from other major economies to their domestic economy while designing domestic policies consistent with higher real economic growth. Similar empirical exercises can be carried out for other emerging economies like South Africa, Mexico, Brazil, etc., including poor economies from Sub-Saharan Africa. 


\section{REFERENCE}

1. Choi, J. W. (2013). The 2007-2010 US financial crisis: Its origins, progressions, and solutions. The Journal of Economic Asymmetries, 10(2), 65-77.

2. Corsetti, G., Pesenti, P., \& Roubini, N. (1998). What caused the Asian currency and financial crisis? Part I: A macroeconomic overview (No. w6833). National Bureau of Economic Research.

3. Nier, E. W., \& Merrouche, O. (2010). What caused the global financial crisis? Evidence on the drivers of financial imbalances, 1999-2007.

4. Mitton, T. (2002). A cross-firm analysis of the impact of corporate governance on the East Asian financial crisis. Journal of financial economics, 64(2), 215-241.

5. Maćkowiak, B. (2007). External shocks, US monetary policy and macroeconomic fluctuations in emerging markets. Journal of monetary economics, 54(8), 2512-2520.

6. Robertson, D., \& Wickens, M. R. (1997). Measuring real and nominal macroeconomic shocks and their international transmission under different monetary systems. Oxford Bulletin of Economics and Statistics, 59(1), 5-28.

7. Mumtaz, H., \& Surico, P. (2009). The transmission of international shocks: a factor- augmented VAR approach. Journal of Money, Credit and Banking, 41, 71-100.

8. Iacoviello, M., \& Navarro, G. (2018). Foreign effects of higher US interest rates. Journal of International Money and Finance.

9. Betts, C., \& Devereux, M. (2001). The international effects of monetary and fiscal policy in a two-country model. Money, Capital Mobility, and Trade: Essays in Honor of Robert A. Mundell, 9-52.

10. Kim, S. (2001). International transmission of US monetary policy shocks: Evidence from VAR's. Journal of Monetary Economics, 48(2), 339-372.

11. Arora, M. V. B., \& Cerisola, M. M. D. (2000). How does US monetary policy influence economic conditions in emerging markets? (No. 0148). IMF Working Paper No. WP/00/148.

12. Canova, F. (2005). The transmission of US shocks to Latin America. Journal of Applied Econometrics, 20(2), 229-251.

13. Di Giovanni, J., \& Shambaugh, J. C. (2008). The impact of foreign interest rates on the economy:
The role of the exchange rate regime. Journal of International economics, 74(2), 341-361.

14. Maćkowiak, B. (2007). External shocks, US monetary policy and macroeconomic fluctuations in emerging markets. Journal of monetary economics, 54(8), 2512-2520.

15. Evgenidis, A., \& Siriopoulos, C. (2015). What is the International Channels through Which a US Policy Shock is transmitted to The World Economies? Evidence from a Time Varying FAVAR (No. 190).

16. Georgiadis, G. (2016). Determinants of global spillovers from US monetary policy. Journal of International Money and Finance, 67, 41-61.

17. Dedola, L., Rivolta, G., \& Stracca, L. (2017). If the Fed sneezes, who catches a cold?. Journal of International Economics, 108, S23-S41.

18. Samargandi, N., \& Kutan, A. M. (2016). Private credit spillovers and economic growth: Evidence from BRICS countries. Journal of International Financial Markets, Institutions and Money, 44, 5684.

19. Arora, V., \& Vamvakidis, A. (2011). China's economic growth: international spillovers. China \& World Economy, 19(5), 31-46.

20. Luke, M., Varfolomeev, I., Lütkepohl, K., \& Esderts, A. (2011). Fatigue crack growth in railway axles: assessment concept and validation tests. Engineering Fracture Mechanics, 78(5), 714730.

21. Mundell, R. A. (1963). Capital mobility and stabilization policy under fixed and flexible exchange rates. Canadian Journal of Economics and Political Science/Revue canadienne de economiques et science politique, 29(4), 475-485.

22. Dornbusch, J. M. (1962). Domestic financial policies under fixed and under floating exchange rates. Staff Papers, 9(3), 369-380.

23. Dornbusch, R. (1976). The theory of flexible exchange rate regimes and macroeconomic policy. The Scandinavian Journal of Economics, 255-275.

24. Corsetti, G., \& Pesenti, P. (2001). Welfare and macroeconomic interdependence. The Quarterly Journal of Economics, 116(2), 421-445.

25. Sims, C. A. (1980). Macroeconomics and reality. Econometrica: Journal of the Econometric Society, 1-48. 
Fig A1: Shows no root lies outside the unit circle and thus, VAR satisfies the stability condition. This is estimated with an optimum lag of 1 based on AIC.

Inverse Roots of AR Characteristic Polynomial

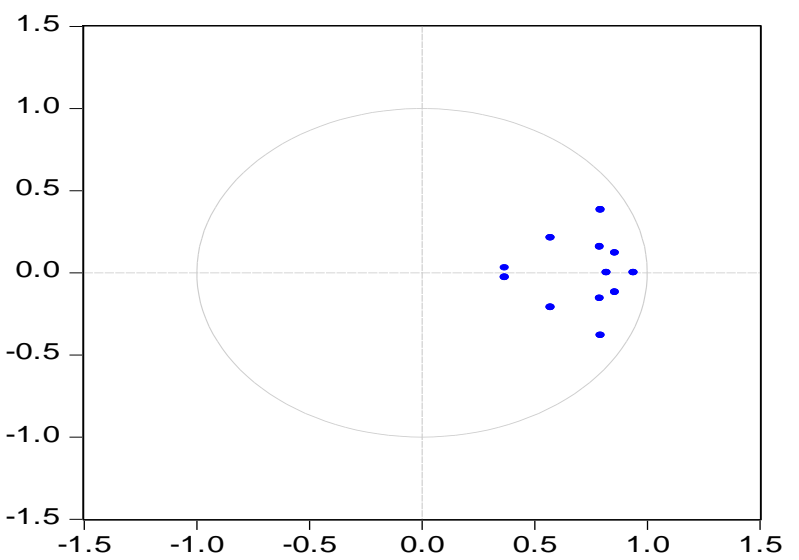

Fig-A1: Model stability result for the base model

Fig-A2: Shows no root lies outside the unit circle and thus, VAR satisfies the stability condition. It is estimated with an optimum lag of 1 based on AIC

Inverse Roots of AR Characteristic Polynomial

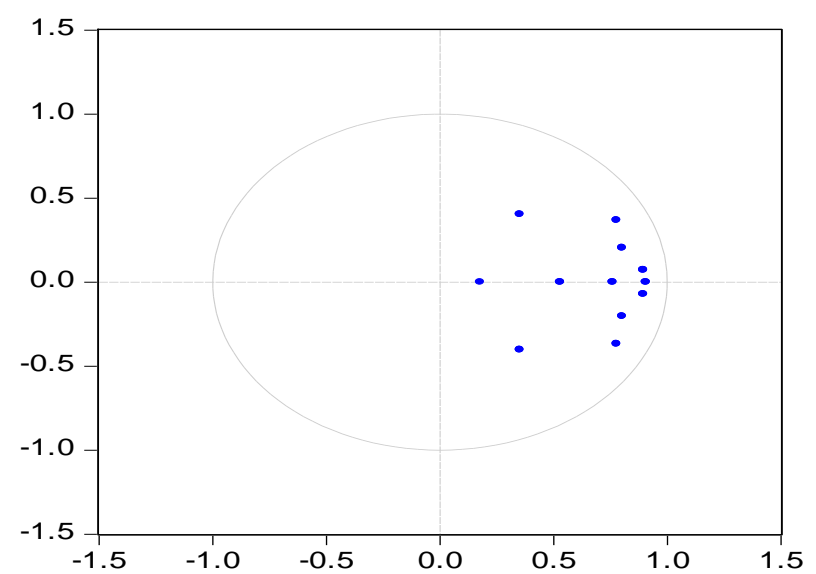

Fig-A2: Model stability result for robustness model 